\title{
LA JURISPRUDENCIA CONSTITUCIONAL COLOMBIANA EN EL AÑO 2015: LA DISCRIMINACIÓN POR RAZÓN DE LA ORIENTACION SEXUAL
}

\section{The Colombian Constitutional Jurisprudence in 2015: Discrimitation Based on Sexual Orientation}

\author{
PAULA ROBLEDO SILVA ${ }^{\top}$ \\ Universidad Externado de Colombia \\ paula.robledo@vexternado.edu.co
}

Cómo citar/Citation

Robledo Silva, P. (2016).

La jurisprudencia constitucional colombiana en el año 2015 :

la discriminación por razón de la orientación sexual. Anuario Iberoamericano de Justicia Constitucional, 20, 565-588.

doi: http://dx.doi.org/10.18042/cepc/aijc.20.19

\section{SUMARIO}

I. INTRODUCCIÓN. II. LA DISCRIMINACIÓN ESCOLAR POR RAZÓN DE LA ORIENTACION SEXUAL:1. La sentencia T-478 de 2015; 2. El derecho a la verdad en los casos de discriminación por orientación sexual. III. EL DERECHO DE LAS PAREJAS DEL MISMO SEXO A ADOPTAR EN IGUALDAD DE CONDICIONES: 1. La sentencia C-683 de 2015; 2. Una decisión activista de la justicia constitucional en clave del interés superior del menor. IV. BIBLIOGRAFÍA.

\footnotetext{
Abogada egresada de la Universidad Externado de Colombia, especialista en Derecho Constitucional y Ciencia Política del Centro de Estudios Políticos y Constitucionales de Madrid, magister en Derecho Público de la Universidad Externado de Colombia y doctora en Derecho por la Universidad de Valladolid. Magistrada auxiliar del Consejo de Estado de Colombia (2010-2014). Actualmente, docente e investigadora en los departamentos de Derecho Constitucional y Administrativo de la Universidad Externado de Colombia y miembro del Consejo Directivo de la Facultad de Derecho de la misma Universidad.
} 
«Una completa igualdad significa más que el logro de objetivos estadísticos; debe cambiar la cultura».

Kofi Annan

\section{INTRODUCCIÓN}

Este escrito ${ }^{2}$ busca presentar una crónica de la jurisprudencia de la Corte Constitucional colombiana durante el año 2015, en relación con la discriminación por razón de la orientación sexual. A través del comentario de dos decisiones judiciales que, a mi juicio, resultaron relevantes durante el año 2015 en Colombia, se pretende reflejar los avances de la jurisprudencia constitucional en materia de derechos fundamentales. Siguiendo la metodología de las ediciones de años anteriores, se han seleccionado dos sentencias: una de tutela (T-478 de 2015), y otra de constitucionalidad (C-683 de 2015), que dan cuenta de cómo el principio de igualdad y la orientación sexual continúan siendo temas muy sensibles para la sociedad colombiana, pero que, poco a poco, evolucionan de la mano del Alto Tribunal Constitucional.

La discriminación con motivo de la orientación sexual se materializa no solo en actos de violencia física y verbal, sino en actitudes diferenciadoras de impacto negativo hacia personas de cierta inclinación sexual — como aquellas contrarias a la heterosexualidad-, con potencialidad de ocasionar vulneración de los derechos fundamentales a la igualdad, al libre desarrollo de la personalidad, a la sexualidad y la dignidad humana, entre otros.

A través de las últimas décadas, numerosas naciones han hecho ingentes esfuerzos por reconocer la diversidad en las personas y consolidar el respeto por la disidencia como lema fundante del progreso del Estado social de derecho. En Colombia, aunque estos cambios no se han dado con premura imperiosa — como debería ser-, sí resalta por su impacto la labor de la Corte Constitucional colombiana y las organizaciones defensoras de los derechos de la Comunidad LGTBI, en la lucha hacia el respeto e igualdad absoluta por el ser humano, sin distinciones en torno al género, la raza, la edad, las creencias religiosas o la inclinación sexual ${ }^{3}$.

2 Este escrito fue realizado con la colaboración de Laura Gallardo, estudiante de posgrado de la Universidad Externado de Colombia.

3 En menos de un siglo, Colombia pasó de penalizar el homosexualismo a reconocer el matrimonio de personas del mismo sexo e incluso permitir la adopción homoparental. Gracias al activo papel de juristas reconocidos en la época, la penalización de la homosexualidad fue abolida con el Código Penal de 1980. No obstante, esta decisión se dio con el único fin de consolidar la separación entre el derecho penal y la moralidad, mas no para proteger el principio de igualdad y reivindicar los derechos de la 
Los avances, sin embargo, son aun incipientes e insuficientes para generar el cambio cultural que requiere la eliminación de todo tipo de discriminación frente a la diferencia en los seres humanos.

\section{LA DISCRIMINACIÓN ESCOLAR POR RAZÓN DE LA ORIENTACION SEXUAL}

En este análisis se abordará un reciente caso de discriminación escolar por orientación sexual, de extrema relevancia por tratarse de un menor de edad, que mereció el estudio por parte de la Corte Constitucional. Se hará énfasis en los argumentos de la Corte para proteger los derechos vulnerados y finalmente se presentará una crítica objetiva al impacto que puede generar el derecho a la verdad en este tipo de decisiones judiciales.

\section{LA SENTENCIA T-478 DE 2015}

En septiembre de 2014, la madre de un menor, un chico de 16 años, quien se suicidó el 4 de agosto del mismo año, instauró una acción de tutela,

comunidad LGTBI; pese a ello, sí se puede considerar un gran avance en materia de reconocimiento de la diversidad sexual en Colombia.

Es importante reconocer la temprana intención del Estado colombiano de crear una sociedad más justa e igualitaria, más aún si se tiene en cuenta que los Estados precursores de la protección de derechos humanos como Francia, Alemania o Estados Unidos presentaron avances significativos en la materia solo hasta después de mitad del siglo $\mathrm{xx}$.

En Colombia, los avances de la jurisprudencia constitucional son notables. La Corte Constitucional mediante la Sentencia C-577 de 2011 reconoció que las parejas del mismo sexo constituyen una familia y exhortó al Congreso de la República para que antes del 20 de junio de 2013 legislara sobre los derechos de las parejas del mismo sexo, con la finalidad de eliminar el déficit de protección que afectaba a las mencionadas parejas; en esa medida, si llegada la fecha señalada el poder legislativo no regulaba la materia, en los precisos términos indicados por la Corte Constitucional, las parejas del mismo sexo podían acudir ante notarios y jueces para solemnizar su vínculo contractual. Posteriormente, mediante Sentencia SU-617 de 2014, la misma Corte aprobó la adopción homoparental. Y recientemente, en Sentencia SU-214 de 2016, la Corte avaló el matrimonio igualitario en el país, lo que significa que ahora parejas del mismo sexo podrán contraer matrimonio civil en las mismas condiciones que lo hacen las parejas heterosexuales, y los notarios no podrán negarse a aprobar el vínculo (se está a la espera de la publicación del texto final de la sentencia). 
alegando que el suicidio de su hijo había sido producto de la constante discriminación y hostigamiento que había sufrido por parte de las directivas del colegio privado en el que se encontraba matriculado — cursando undécimo grado-, una vez tuvieron conocimiento de la orientación homosexual del menor.

En la demanda, la accionante solicitó la protección constitucional de los derechos a la intimidad y buen nombre de su hijo, así como a la igualdad y no discriminación, al libre desarrollo de la personalidad, a la educación, y a la prevalencia de los derechos de los niños, vulnerados sistemáticamente por el colegio Gimnasio Castillo Campestre, la Secretaría de Educación de Cundinamarca, el Instituto Colombiano de Bienestar Familiar - ICBF-, la Fiscalía General de la Nación y la Comisaría Décima de Familia de Engativá.

La historia de Sergio Urrego, el menor víctima de acoso y discrimnación, se remonta al mes de mayo de 2014, cuando aparentemente uno de los profesores de la institución educativa implicada decomisó el teléfono celular de una alumna y descubrió una fotografía en la que el menor se daba un beso con uno de sus compañeros de clase. A partir de ese momento, el colegio desplegó una serie de actuaciones intimidatorias y hostigantes contra los estudiantes que aparecían en la foto, al punto de difundir públicamente ante la comunidad académica la situación de homosexualidad que se estaba presentando, procediendo incluso a abrir investigación disciplinaria contra el joven Urrego por haber incurrido en una falta grave contra el Manual de Convivencia del colegio, debido a las «manifestaciones de amor obscenas, grotescas o vulgares» que, según la institución educativa, se evidenciaron en la fotografía. Por tal situación, los padres del disciplinado fueron citados en repetidas ocasiones a comparecer a la institución, y el menor implicado obligado a asistir permanentemente a consultas psicológicas y psiquiátricas.

A manera de correctivo, la psicóloga del colegio advirtió a Sergio y su compañero que no debían incurrir nuevamente en la mencionada falta y, como garantía, estos suscribieron una carta de compromiso para mantener distancia entre ellos. Los requerimientos del colegio continuaron, razón por la cual la madre del menor presentó ciertas quejas ante las autoridades administrativas competentes para proteger los derechos de los menores y los estudiantes, sin obtener resultados concretos y oportunos.

Paralelamente, la madre de Sergio Urrego fue notificada de dos investigaciones que se estaban adelantando: una en contra de su hijo y otra en contra de ella. La primera se refería a una denuncia penal por acoso sexual que había sido interpuesta contra Sergio Urrego por los padres de su compañero de clase (con quien se besó); y la segunda se trataba de una denuncia administrativa por aparente abandono de hogar formulada en contra de ella ante el Instituto Colombiano de Bienestar Familiar - ICBF_ y la Comisaría de Familia. 
Luego de casi dos meses de lidiar de investigación disciplinaria en el colegio y procesos de tipo penal y administrativos, Sergio David Urrego se suicidó, lo que de manera inmediata produjo la reacción y reclamo de organizaciones defensoras de los derechos de los niños, de las minorías sexuales, de la población LGTBI y de la comunidad en general.

Como consecuencia de la polémica suscitada en torno a la problemática de discriminación en los colegios colombianos y ante la acción constitucional instaurada por la madre de la joven víctima, se produjo un pronunciamiento ejemplar por parte de la Corte Constitucional colombiana. Mediante la Sentencia T-478 de 2015 el Alto Tribunal ordenó la regulación e implementación de mecanismos de protección frente a situaciones de discriminación escolar e impuso, en el caso concreto, medidas de reparación simbólica como garantía de conservación de la memoria histórica.

La Corte Constitucional se ocupó de analizar varios aspectos, entre los cuales se destacan, para los efectos de este escrito, los relativos al a) el derecho a la igualdad; b) la prohibición de discriminación escolar en razón de la orientación sexual, y c) las medidas de reparación simbólica en este tipo de casos.

En primer lugar, el máximo órgano de la jurisdicción constitucional hace un recuento de la jurisprudencia que ha proferido en torno a la protección del derecho a la igualdad, especialmente en ambientes educativos en los que se presenta algún tipo de discriminación por la inclinación sexual de un estudiante ${ }^{4}$. En estos pronunciamientos, la Corte ha concebido la orientación sexual de los niños y adolescentes como un elemento consustancial al ser humano, que hace parte del núcleo esencial de su dignidad, libertad y autonomía.

Tal razonamiento representó en su momento un gran avance en materia de protección de los derechos fundamentales de la población LGTBI, pues reconoció que la liberalidad de determinar la inclinación sexual es un derecho inherente al ser humano y que, por ende, corresponde a la esfera interna de cada persona la cual se sustrae de los principios religiosos y morales imperantes en la sociedad en la cual se vive.

La jurisprudencia constitucional ha sido constante en vincular la protección del derecho a elegir libremente una orientación sexual al derecho fundamental a la igualdad, pero paulatinamente también lo ha ido vinculado a otros derechos fundamentales como la dignidad humana y el libre desarrollo

\footnotetext{
A manera de ejemplo, la Corte hizo alusión a las sentencias T-435 de 2002, T-565 de 2013 y T-804 de 2014, a través de las cuales amparó los derechos de tres menores a quienes les habían sido impuestas sanciones académicas por motivo de su orientación sexual.
} 
de la personalidad 5 , bajo el entendido de que la tendencia sexual es un aspecto íntimamente ligado a la identidad de cada persona.

La Corte ${ }^{6}$ también señaló que bajo el amparo del respeto del principio de la dignidad humana ${ }^{7}$ y de la cláusula del Estado social de derecho, se han impuesto múltiples sanciones administrativas y judiciales a instituciones educativas tanto públicas como privadas, que han pretendido implantar en los alumnos sus creencias o regulaciones por encima de la autonomía que corresponde a cada uno de estos individuos, en contravía de la posición crucial en que se encuentran los colegios con respecto a sus estudiantes, quienes atraviesan por una etapa de formación y reconocimiento de su personalidad.

Para calcular en cifras la situación de acoso escolar en Colombia, el Alto Tribunal, en la decisión objeto de análisis, acudió a los precarios estudios de intimidación escolar publicados en el país ${ }^{8}$ para denotar que este es un fenómeno extendido y masivo en el sistema educativo colombiano. En cuanto al acoso por motivo de la orientación sexual, encontró que al menos el $30 \%$ de los menores que demuestran una inclinación homosexual es rechazado por estudiantes y/o autoridades de la institución educativa, entre los grados $5^{\circ}$ a $11^{\circ}$

5 Ver, por ejemplo, entre las sentencias de la Corte Constitucional, las siguientes: C-336 de 2008, T-090 de 96 y T-881 de 02.

6 Sentencia T-804 de 2014, mediante la cual se reconoció expresamente que «el núcleo esencial de la dignidad humana supone que la persona sea tratada de acuerdo a su naturaleza humana, y el Estado, dentro de sus fines esenciales, debe preservar la libertad, la autonomía y la integridad física y moral de estos ciudadanos. En esa medida, el respeto a la dignidad humana en los establecimientos educativos implica aceptar a cada individuo como es, con sus rasgos, características y diferencias específicas en tanto que esa misma individualidad es la que distingue a cada sujeto de la especie humana».

7 El preámbulo de la Constitución Política de 1991 consagra como fundamento la intención de asegurar al pueblo de Colombia la justicia y la igualdad. Así, en el art. 2 de esa disposición contempló como uno de los fines esenciales del Estado garantizar la efectividad de los principios, derechos y deberes de rango constitucional (como la dignidad, la igualdad y el libre desarrollo de la personalidad), y más adelante, en el art. 5 consignó que el Estado reconoce, sin discriminación alguna, la primacía de los derechos inalienables de la persona.

8 Las fuentes utilizadas fueron presentadas por la Secretaría de Gobierno de Bogotá (2008) y Chaux (2008). Los estudios concretos sobre discriminación escolar por orientación sexual, se realizaron entre los grados $5^{\circ}$ y $11^{\circ}$ y evidenciaron el porcentaje de estudiantes que reporta que algún compañero de clase fue rechazado durante el mes pasado por ser homosexual y el porcentaje de estudiantes que afirman estar más o menos de acuerdo, o totalmente de acuerdo, con la afirmación «en mi colegio deberían sacar a los homosexuales». 
de escolaridad. De otra parte, la Corte también evidenció que en Colombia existe mayor tolerancia hacia la diversidad sexual por parte de las mujeres, que en relación con los hombres.

A partir de los estudios recopilados, la Corte se encargó de establecer una lista de los deberes y obligaciones de la comunidad académica en relación con la protección de la dignidad humana y los derechos fundamentales de sus estudiantes, siendo oportuno mencionar los siguientes hallazgos: a) los manuales de convivencia aprobados por los colegios son una expresión de su filosofía, pero deben consultar los intereses, preocupaciones y visión de los miembros a quienes va dirigido como garantía del derecho al debido proceso, además de que las sanciones que contemple deben perseguir un fin constitucionalmente legítimo; b) aquellas conductas de los estudiantes que no interfieran ni entorpezcan la actividad académica ni comprometan el nombre de la institución, no pueden ser sancionadas disciplinariamente porque hacen parte del desarrollo privado y autónomo del individuo, y c) el respeto por la diversidad, la pluralidad y el multiculturalismo en el proceso de enseñanza y aprendizaje, es un rasgo presente en el modelo de Estado social de derecho.

Ahora bien, con el fin de determinar si existió discriminación escolar en el caso concreto, la Corte partió del supuesto de que en Colombia existe todo un marco normativo y de política pública dirigido a prevenir y sancionar el acoso escolar, definidos en la Ley 1620 de 2013 y su Decreto Reglamentario 1965 de 2013, para concluir que ninguna de las entidades demandadas recorrió las rutas de acción establecidas para prevenir y mitigar las conductas que ellos consideraron censuradas. Para la Corte, esta actitud demuestra que en Colombia hay una escasa difusión, entre las instituciones académicas y las autoridades administrativas encargadas de la protección de los derechos de los menores, del marco legal que debe regir situaciones como la de Sergio Urrego.

Si bien la Corte, en uso de su sana crítica, acertadamente concluyó que Sergio David Urrego Reyes fue víctima de acoso escolar y discriminación por parte del colegio debido a su orientación sexual y que ello configuró una violación al derecho al debido proceso dentro de la investigación disciplinaria que se le abrió por desconocimiento de los derechos al libre desarrollo de la personalidad y la dignidad, es reprochable que la Corte no haya establecido una relación de causalidad entre esos eventos y el suicidio del joven.

Debió ser suficiente para la Corte, a fin de establecer ese nexo causal, el hecho de encontrar plenamente acreditada — como ella misma advirtió en la providencia - la persecución que recibió la víctima una vez se conoció su orientación sexual, que lo llevo a: a) separarse abruptamente de su compañero sentimental; b) estar involucrado en un proceso disciplinario en la institución educativa donde estudiaba, así como en uno penal por acoso sexual patrocinado por el ente académico a sabiendas de la relación homosexual consentida 
que ostentaba con uno de sus compañeros; c) adicionalmente, estar involucrado en una investigación administrativa que controvertía la integridad de su núcleo familiar, y d) especialmente, tomar la decisión de suicidarse debido en gran parte a la discriminación recibida por el colegio, tal como lo señaló en las cartas de despedida.

En la sentencia, el reproche de la situación de discriminación dio lugar a la imposición de una serie de medidas de reparación simbólica a cargo de la institución educativa y de la orden de implementar de forma vigorosa las acciones complementarias requeridas para la aplicación del Sistema Nacional de Convivencia Escolar' ${ }^{9}$, las cuales, sea de paso procedente señalar, que resultan insuficientes para erradicar el problema cultural de homofobia en Colombia, pues es imprescindible garantizar también el derecho a la verdad en el caso concreto, lo que denota una falla desde el punto de vista de la protección de los derechos fundamentales vulnerados.

\section{EL DERECHO A LA VERDAD EN LOS CASOS DE DISCRIMINACIÓN POR ORIENTACIÓN SEXUAL}

Como se mencionó, en la Sentencia T-478 de 2015, pese a abundante material probatorio, la Corte rechazó pronunciarse expresamente sobre el nexo de causalidad que pudo existir entre la discriminación por orientación sexual que padeció Sergio David Urrego Reyes y su muerte, limitándose a afirmar que si bien el joven reconoció en sus cartas de despedida que los problemas en el colegio fueron determinantes para tomar su decisión, «lo cierto es que para un adolescente, los múltiples factores que incidieron en este periodo, - como los procesos penales y disciplinarios en curso, la separación de Horacio ${ }^{10}$, la situación familiar generada por la distancia física con sus padres, la presión del

9 Este sistema fue creado por la Ley 1620 de 2013, como un instrumento dirigido a la conservación de la convivencia escolar, y formación de los derechos humanos, la educación para la sexualidad y la prevención y mitigación de la violencia escolar. Entre sus objetivos, se cuentan la protección integral de los niños, niñas y adolescentes en los espacios educativos a través de la puesta en marcha de la ruta de atención integral para la convivencia escolar, el fomento y fortalecimiento del desarrollo de la identidad, así como la promoción de estrategias para la detección, atención y seguimiento de los casos de violencia escolar, acoso escolar o vulneración de derechos sexuales y reproductivos. Uno de los principios del Sistema es la diversidad, esto es, el reconocimiento, respeto y valoración de la dignidad propia y ajena, sin discriminación por razones de género, orientación o identidad sexual, etnia o condición física, social o cultural.

10 Nombre que la Corte le asignó al otro menor involucrado en el beso, para proteger su identidad y su derecho a la intimidad. 
colegio, sus ideas particulares, el deber de analizar su orientación sexual, etc., pudieron contribuir de un modo u otro a la triste conclusión de su partida».

De la anterior reflexión, se aprecia que la Corte omitió dar protección al derecho a la verdad en el caso concreto, pues desconoció que la multiplicidad de sucesos que pudieron incidir en la decisión del menor tuvieron su raíz en la situación de discriminación y acoso a que fue expuesto desde el momento en que se conoció su orientación sexual, es decir, a partir de que las directivas del colegio le negaron un rasgo propio de su misma humanidad: la libertad de elegir sus preferencias sexuales.

La importancia de reconocer el derecho a la verdad en los casos de discriminación escolar yace en el deber de entregar a la sociedad toda la información que merece conocer para asegurar la efectividad de la justicia. El juez de tutela tiene el deber constitucional y convencional de garantizar la vigencia de la Constitución Política y la legislación internacional que hace parte del bloque de constitucionalidad, instrumentos que reconocen la vigencia de los derechos a la dignidad humana, la igualdad, el libre desarrollo de la personalidad y la verdad.

En efecto, la Comisión Interamericana de Derechos Humanos en el análisis de diversos casos ${ }^{11}$ ha manifestado que el derecho a la verdad es una

11 La Comisión Interamericana de Derechos Humanos - CIDH - en cumplimiento del mandato emanado por la Asamblea General de la Organización de los Estados Americanos en Resolución AG/RES, 2175, publicó en el año 2014 un informe denominado Derecho a la verdad en las Américas orientado a divulgar los estándares sobre el derecho a la verdad, el marco jurídico aplicable y el análisis de algunas experiencias implementadas en la región, frente a casos de graves violaciones de derechos humanos e infracciones al DIH por parte de los Estados. En el estudio, reconoció que a la luz de los preceptos contenidos en la Convención Americana de Derechos Humanos, se reconoce el derecho de las víctimas y sus familiares a conocer la verdad con respecto a los hechos que dieron lugar a graves violaciones de los derechos humanos, así como el derecho a conocer la identidad de quienes participaron en ellos.

La Organización de las Naciones Unidas, por su parte, en su página web publica un artículo referente al derecho a la verdad (Relatoría Especial para la Libertad de Expresión, $\mathrm{CIDH}$ ) en el que establece que la $\mathrm{CIDH}$ ha interpretado el derecho a la verdad, con base en los artículos 1, 8, 13 y 25 de la Convención Americana sobre Derechos Humanos, el cual pertenece a las familias y a toda la sociedad ante la vulneración de derechos fundamentales, y se extiende al derecho a obtener y recibir información acerca de lo ocurrido, sus razones y los responsables, a fin de evitar que esos hechos vuelvan a ocurrir en el futuro. En el caso Castillo Páez (3 de noviembre de 1997), la CIDH señaló que las «obligaciones genéricas del artículo 1.1, permiten concluir que el 'derecho a la verdad' surge como una consecuencia básica e indispensable para todo 
consecuencia básica e indispensable para todo Estado parte porque protege el derecho de la sociedad a obtener y recibir información, así mismo forma parte del derecho de las víctimas y/o sus familiares a una reparación.

Para explicar la crítica que se hace al pronunciamiento de la Corte, debe partirse de la base de que como garantía del derecho a la identidad — parte integrante del derecho fundamental a la dignidad humana-, procede erradicar desde todos los ámbitos sociales y, principalmente, desde el jurídico la posibilidad de endilgar al mero hecho de tener una orientación sexual disidente (a partir de la heterosexualidad) una consecuencia adversa a la salud mental ${ }^{12}$ del ser humano. Esto significa que la elección de una preferencia sexual, por sí sola, no genera en una persona el deber de cuestionar su existencia en el mundo; sin embargo, por el contrario, la presión, maltrato, discriminación y rechazo sobre esa inclinación sí pueden producir desequilibrios en la psique de quien no encuentra aceptación dentro de los seres de su misma especie, especialmente de aquellos que lo rodean.

El cambio cultural que se requiere para erradicar la discriminación por identidad de género debe partir de la concepción de la elección de la orientación sexual como un rasgo natural de la humanidad. Esa libertad de elección

Estado parte». En el caso 10480 referida al El Salvador (22 de diciembre de 1999), la misma Corte sostuvo que el derecho a la verdad «es un derecho de carácter colectivo que permite a la sociedad tener acceso a información esencial para el desarrollo de los sistemas democráticos y, un derecho particular para los familiares de las víctimas, que permite una forma de reparación». Una reseña de la publicación se puede encontrar en http://www.oas.org/es/cidh/expresion/showarticle.asp?artID=156\&lID=2.

12 Se menciona la afectación de la salud mental bajo el entendido que el suicidio obedece en la mayoría de los casos a un desorden psicológico ligado a trastornos mentales. La Federación Mundial para la Salud Mental (2010), estableció como causas de suicidio el trastorno depresivo mayor, graves oscilaciones del ánimo, presencia de síntomas psicóticos — presente en personas bipolares y esquizofrénicas.

La Asociación Americana de Suicidiología (American Association of Suicidology) en su publicación Suicidal behaviour among lesbian, gay, busexual and transgender youth encontró que los jóvenes con orientación sexual diferente a la heterosexualidad son más propensos a cometer suicidio, no porque ser parte de la comunidad LGBT sea un factor de riesgo en sí mismo, sino por los factores de estrés a los que se enfrentan como discriminación, acoso y violencia, que pueden desencadenar en desordenes psiquiátricos, depresión y ansiedad. El abuso de sustancias es un factor que también puede incidir en el suicidio. Disponible en: http://www.suicidology.org/ Portals/14/docs/Resources/LGBT\%20Resources/SuicidalBehaviorAmongLGBTYouthFacts.pdf y http://www.suicidology.org/Portals/14/docs/Resources/LGBT\% 20Resources/LGBTresource-sheet.pdf. 
en cuanto a la sexualidad, se equipara a la libertad de elegir profesión, religión o un partido político, pues al igual que en esos casos, pertenece a la esfera privada y, en tanto sea una expresión de la autonomía personal, no afecta al individuo ni a la comunidad.

El mero hecho de pensar que poseer una orientación sexual disidente puede dar lugar a producir un trastorno mental en el ser humano se traduce en un trato diferenciador con respecto a la heterosexualidad, que avala la injerencia de un modelo social que ha impuesto sus conceptos preconcebidos sobre lo «normal» $\mathrm{o}$ «natural».

En el caso de Sergio David Urrego Reyes, el rechazo demostrado por los directivos del colegio frente a su homosexualidad, la inactividad de los entes administrativos al respecto, y las acciones y omisiones que se derivaron de esa fobia, fueron en su conjunto las que provocaron tal desequilibrio emocional en su ser que lo llevó al límite de cuestionar su propia existencia y considerarla insoportable.

Por lo tanto, sí fue el acoso y discriminación los que contribuyeron directamente a la decisión radical que lo llevó a acabar con su vida y esa era una verdad que la sociedad tenía derecho a conocer. La Corte debió entonces aceptar que la investigación disciplinaria abierta por el colegio, el proceso penal interpuesto por acoso sexual, el cuestionamiento del hogar de la víctima ante el Instituto Colombiano de Bienestar Familiar, la obligada separación de su amigo sentimental y el deber de analizar su orientación sexual, tuvieron por génesis su tendencia homosexual.

El reconocimiento del nexo de causalidad entre la discriminación y el suicidio resultaba entonces relevante, no para obtener en la sentencia de tutela un juicio de responsabilidad penal o civil con la consecuente imposición de sanciones pecuniarias y restrictivas de la libertad, pues es evidente que esa potestad no está dentro de la órbita del juez constitucional, sino para asegurar la protección de los derechos a la verdad, a la memoria como parte fundamental del patrimonio familiar, al buen nombre y a la dignidad misma del lesionado.

Aislar el hecho de discriminación de la muerte, es desconocer el impacto de la vulneración de los derechos fundamentales transgredidos. Esto se denota en la sentencia estudiada, en la que, aunque se concluyó que existió acoso por motivo de la orientación sexual, finalmente se desconoció el alcance letal que este tuvo.

El sistema judicial colombiano, ya en casos anteriores, ha reconocido que a partir de ciertas actuaciones se induce a una persona al suicidio. Una forma de inducir esa conducta es precisamente el maltrato emocional y las presiones hacia la víctima, bajo el entendido de que a partir de ellas se contribuye a la materialización del «daño», en este caso el suicidio. 
Ciertamente, el Consejo de Estado —-máximo tribunal de la jurisdicción de lo contencioso administrativo- en diversos pronunciamientos ${ }^{13}$ ha endilgado responsabilidad al Estado, cuando a través de la actuación u omisión de sus agentes ${ }^{14}$ induce el suicidio de una persona o contribuye a que este se lleve a cabo, justamente al reconocer la relación de causalidad que existe entre los antecedentes de acoso y un hecho posterior como el suicidio.

La jurisdicción de lo contencioso administrativo incluso ha reconocido como agravante de la conducta nociva el haber sido perpetrada en contra de menores de edad dada su incapacidad psíquica o inmadurez que los sitúa en un espacio de mayor indefensión, o sobre las personas en quienes el agente estatal implicado ejerce la guarda o custodia, debido a la sumisión de los primeros hacia los segundos.

Si bien la Corte Constitucional goza de autonomía para realizar juicios en los casos que llegan a su conocimiento y de libertad para encauzarlos de

13 Ver por ejemplo, la sentencia proferida por el Consejo de Estado, Sección Tercera, de 30 de septiembre del 2000, exp. 13 329, cuya tesis jurisprudencial fue reiterada en las sentencias de 8 de julio de 2009, exp. 17410 y 17 527, donde se estableció que "para que surja el deber del Estado de reparar el daño causado por el suicidio de un recluso o un conscripto es necesario acreditar que por el trato que recibía en el establecimiento militar o carcelario fue inducido a tomar esa decisión"; sentencia de 30 de noviembre de 2000, exp: 13229 en la que se sostuvo que «el Estado no es patrimonialmente responsable de los daños sufridos por los miembros de las instituciones armadas cuando éstos se producen como consecuencia de la propia actuación de la víctima, salvo cuando existe el deber de custodia y protección de esas personas, por tratarse de menores de edad; o cuando su decisión no se produce de manera voluntaria sino como consecuencia de presiones ejercidas sobre ella, imputables a la administración»; sentencia de 23 de septiembre de 2009, rad. 18272, que anotó "para que surja el deber del Estado de reparar el daño causado por el suicidio de un recluso o un conscripto es necesario acreditar que por el trato que recibía en el establecimiento militar o carcelario fue inducido a tomar esa decisión», y la sentencia de 5 de marzo de 2004, exp. 1996-00432 01, que condenó un caso de suicidio inducido, bajo el siguiente argumento: «Hay lugar a derivar responsabilidad del Estado porque se demostró la falla de servicio, materializada en el incumplimiento de las obligaciones que le impone la ley (...). Son varias razones: a. Se demostró que el soldado Tirado Vargas recibió maltrato en el establecimiento militar, que lo indujo a tomar la decisión de suicidarse. Así se desprende de las numerosas declaraciones recibidas por el investigador penal militar, en las que se evidencian los maltratos físicos y emocionales a que eran sometidos los soldados por el capitán Maury Campo, comandante del escuadrón», entre otras.

14 Acciones u omisiones tales como maltrato físico y/o verbal, discriminación, trato diferenciado, negación de derechos, negación en la prestación de servicios de psicología y psiquiatría, entre otros. 
conformidad con su sana crítica, resulta cierto también que el ejercicio de sus funciones supone ofrecer protección general a todos los derechos fundamentales que puedan estar comprometidos, dentro de ellos el derecho a la verdad.

El derecho a la verdad ha sido analizado en Colombia, principalmente en el marco del conflicto armado interno, frente a graves violaciones de derechos humanos ${ }^{15}$. A este derecho se le han atribuido objetivos que van más allá de establecer responsabilidad individual, como la posibilidad de contribuir al restablecimiento y mantenimiento de la paz, la reconciliación, la prevención de violaciones futuras, la reparación y la reafirmación del principio de legalidad ${ }^{16}$.

La aplicación que mayormente se le ha dado a este derecho en Colombia, no implica que esté limitado a los casos de violaciones graves de derechos humanos dentro del conflicto armado interno, sino que se extiende a toda clase de vulneración de derechos humanos, pues también en estos casos el Estado, en este caso a través de la Corte Constitucional, tiene la obligación de proporcionar información a las víctimas, a sus familiares y a la sociedad sobre las circunstancias en que se cometieron tales violaciones, a la luz de lo dispuesto en la Constitución Política y en los instrumentos internacionales acogidos por Colombia ${ }^{17}$.

15 Se ha analizado el derecho a la verdad en el marco de la Ley 1448 de 2011 «por la cual se dictan medidas de atención, asistencia y reparación integral a las víctimas del conflicto armado interno y se dictan otras disposiciones», que estableció un conjunto de medidas judiciales, administrativas, sociales y económicas, individuales y colectivas, en beneficio de las víctimas de las violaciones graves y manifiestas a las normas internacionales de derechos humanos, ocurridas con ocasión del conflicto armado interno. La Comisión Interamericana de Derechos Humanos ha indicado que la verdad, la justicia, la reparación y las garantías de no repetición contribuyen al logro de diversos objetivos, entre ellos: a) a ofrecer reconocimiento a las víctimas y fomentar la confian$\mathrm{za}, \mathrm{b})$ a contribuir a la reconciliación y reforzar el estado de derecho. Dado que estos pilares son complementarios pero tienen un contenido y alcance propios, «la verdad no puede ser un sustituto de la justicia, la reparación o las garantías de no repetición» puntualiza. En contextos de transición, por ejemplo, ha indicado la CIDH que «el logro de una verdad completa, veraz, imparcial y socialmente construida, compartida, y legitimada es un elemento fundamental para la reconstrucción de la confianza ciudadana en la institucionalidad estatal».

17 El art. 20 de la Constitución establece que «se garantiza a toda persona la libertad de expresar y difundir su pensamiento y opiniones, la de informar y recibir información veraz e imparcial (...). Se garantiza el derecho a la rectificación en condiciones de equidad». Por su parte, la Comisión Interamericana de Derechos Humanos, como se anotó en precedencia, ha entendido que el derecho a la verdad se encuentra subsumido en el derecho a la libertad de expresión contenido en el art. 13 de la Con- 
Visto todo lo anterior, puede pensarse que la Corte Constitucional al estudiar el caso de Sergio David Urrego Reyes debiera haber cumplido con su deber de proteger el derecho fundamental a la verdad sobre los hechos que rodearon su muerte y tendría que haber aceptado abiertamente la contribución activa del colegio accionado en el desenlace nefasto que siguió al episodio de hostigamiento, acoso y discriminación: el suicidio de Sergio David.

Con una reflexión de este tenor, se hubiera contribuido a lograr fines que son esenciales al derecho a la verdad, entre ellos: a) a restablecer y mantener la paz, pues al exponer la verdad la sociedad estaría en capacidad de detectar a tiempo futuros casos de discriminación por orientación sexual y prevenir sus consecuencias; b) a facilitar los procesos de reconciliación, toda vez que conocer la verdad es una manera de materialización de la justicia; c) a erradicar la impunidad, porque el conocer la verdad permite hacer un reproche público de las conductas que atentan contra la diversidad sexual, y posibilita que el victimario reconozca y dimensiones el impacto de sus acciones, y d) a reparar a las víctimas, en tanto la efectividad del derecho a la verdad es por sí misma una forma de reparación.

La imputación del suicidio al episodio de discriminación que padeció la víctima era entonces indispensable para asegurar la memoria ${ }^{18}$, el buen nombre $^{19}$ y la dignidad del lesionado ${ }^{20}$ y su familia: a) la memoria como parte fun-

vención Americana sobre Derechos Humanos. Ha entendido la $\mathrm{CIDH}$ igualmente que el derecho a la verdad guarda relación con el derecho de acceso a la información, contemplado en el art. IV de la Declaración Americana sobre los Derechos y Deberes del Hombre.

18 La Corte Constitucional ha indicado que la memoria hace parte del patrimonio familiar y es de invaluable importancia, en tanto se refiere al recuerdo y reputación que una persona conserva sobre su familiar fallecido. Esos recuerdos son un vínculo latente entre quien dejó de existir y su entorno, por tanto la protección de la memoria busca que se conserve ese recuerdo, evitando que de manera temeraria o imprudente se afecte. Este entendimiento lo explica la Corte en la sentencia que se revisa (T-478 de 2015).

19 La Corte Constitucional lo ha definido como «la reputación o el concepto que de una persona tienen los demás» y «la estimación o deferencia con la que, en razón a su dignidad humana, cada persona debe ser tenida por los demás miembros de la colectividad que le conocen y le tratan». Ver por ejemplo, sentencias T-405 de 2007, T-977 de 1999, C-498 de 2002 y T-634 de 2013.

20 Es pertinente traer a colación la definición que la Corte Constitucional realizó sobre la dignidad humana en sentencia T-881 de 2002: «La Sala ha identificado a lo largo de la jurisprudencia de la Corte, tres lineamientos claros y diferenciables: (a) la dignidad humana entendida como autonomía o como posibilidad de diseñar un plan vital y 
damental del patrimonio familiar, teniendo en cuenta lo valioso que es para la familia la conservación del recuerdo de su ser fallecido; b) el buen nombre de Sergio, para mitigar su responsabilidad en el suicidio y otorgarle la calidad de víctima, y c) la dignidad humana, mediante el reconocimiento de que su orientación sexual era un derecho inalienable que le asistía, el cual no debió obligarlo nunca a cuestionar su existencia, sino por el contrario, debió ser respetado y protegido por el colegio y la sociedad.

Adicionalmente, reconocer la existencia de un suicidio inducido por motivo de discriminación por orientación sexual en la jurisprudencia constitucional, hubiera guardado consonancia con el precedente que existe en la jurisdicción contencioso administrativa frente a casos similares de acoso e intimidación, lo cual constituiría un aporte significativo a la concreción de la igualdad de protección y trato frente a personas que se encuentran en similar situación de hecho y, de paso, ofrecería una garantía mínima a la seguridad jurídica, la buena fe y la coherencia del orden jurídico colombiano.

Con el reconocimiento de la discriminación como causa directa del suicidio, cobran fuerza las medidas de reparación simbólica impuestas por la Corte Constitucional, cuya finalidad es atenuar la situación de vulneración ante la imposibilidad de reparar el daño causado, garantizar su no repetición, preservar la memoria histórica y generar espacios para la reconciliación. El hallazgo de la verdad en el caso de Sergio David Urrego Reyes, en sí misma, es una medida de reparación de inmensurable impacto, comoquiera que recuerda a la comunidad una certeza absoluta, y es la inalienabilidad del derecho a ser, inherente a la raza humana, dentro del que se aloja el resguardo de las actitudes personalísimas en las que no caben legítimamente las intromisiones. Le recuerda, además, la gravedad de que episodios de discriminación por orientación sexual se vuelvan a presentar y las consecuencias irreparables que puede generar en las víctimas.

A partir de la anterior crítica, se procura abordar un punto necesario en la búsqueda de la equidad que, aunado al buen ejercicio desarrollado por la Corte Constitucional en la lucha contra la discriminación por razones de la orientación sexual, puede contribuir al cambio cultural que se requiere en sociedad colombiana.

de determinarse según sus características (vivir como quiera); b) la dignidad humana entendida como ciertas condiciones materiales concretas de existencia (vivir bien), y c) la dignidad humana entendida como intangibilidad de los bienes no patrimoniales, integridad física e integridad moral (vivir sin humillaciones). 


\section{EL DERECHO DE LAS PAREJAS DEL MISMO SEXO A ADOPTAR EN IGUALDAD DE CONDICIONES}

Como quiera que en los procesos de adopción lo relevante es siempre el interés superior del menor, porque lo que se pretende no es dar un niño a una familia sino una familia a un niño, que la necesita y tiene derecho a ella, la Corte Constitucional, a través de la Sentencia C-683 de 2015, se encarga de examinar si la adopción por parte de personas con orientación sexual diversa, en particular por familias conformadas por parejas del mismo sexo, afecta o amenaza el desarrollo integral y armónico de los menores. La Corte resuelve declarar la exequibilidad condicionada de las normas demandadas, siempre y cuando se entienda que las parejas del mismo sexo que constituyen una familia también pueden adoptar niñas, niños y adolescentes, en aras de garantizar la protección del interés superior del menor.

En esta ocasión, la Corte Constitucional colombiana llega a una decisión activista que introduce al ordenamiento jurídico del país una interpretación que tiene como componente determinante la evolución social y cultural, y por esta vía la inclusión de las parejas del mismo sexo como posibles padres adoptantes, en aras de la garantía del interés superior del menor, representado en su derecho a tener una familia para garantizar su desarrollo armónico e integral (art. $44 \mathrm{CP})$.

\section{LA SENTENCIA C-683 DE 2015}

A juicio de los accionantes, las leyes 54 de 1990 y 1098 de 2006 excluyen la posibilidad de que los niños sean adoptados por parejas conformadas por personas del mismo sexo. Los demandantes cuestionaron justamente dichas disposiciones, en esencia, por vulnerar el derecho a la igualdad y el interés superior de los niños que permanecen en situación de adoptabilidad, al limitar sin justificación suficiente el universo de familias que pueden adoptarlos. También adujeron que hubo una omisión relativa del legislador, violatoria del interés superior de los niños, porque la ley no consagró claramente una regulación para la adopción de niños por parejas del mismo sexo, lo que supone una desprotección de la niñez. Finalmente, observaron que existe una interpretación dominante en la administración pública (ICBF y Procuraduría General de la Nación), orientada a desproteger a los niños, que reduce el universo de familias potencialmente adoptantes, en cuanto excluye a las parejas del mismo sexo en detrimento de los derechos de los niños.

En primer lugar, advierten que se vulnera la igualdad ya que se omite proteger el interés prevalente del menor en situación de adoptabilidad, representado en su derecho fundamental a tener una familia. Añaden que ese derecho 
hace parte del interés superior del menor, donde la adopción es el principal mecanismo de protección. Sobre esa base se preguntan lo siguiente: «iSi los niños huérfanos son titulares del derecho fundamental a una familia y pueden ejercerlo a través de la adopción solicitada por una pareja heterosexual, existe alguna razón que impida que puedan ser igualmente adoptados por parejas homoparentales, máxime cuando estas constituyen familia según la sentencia C-577 de 2011?».

Con la advertencia de que la adopción es por esencia el principal mecanismo de protección de los niños en determinadas circunstancias, aseguran que «si el objetivo de nuestro ordenamiento jurídico y de la normativa internacional es la efectiva protección del interés prevalente de los niños, niñas y adolescentes, representado en su derecho fundamental a tener una familia, negarles la posibilidad de que sean adoptados por una pareja homosexual implica una violación de los derechos y obligaciones arriba mencionados y una infracción de la Constitución Política y el bloque de constitucionalidad».

Consideran también que restringir el derecho fundamental del menor a tener un solo tipo de familia, la heterosexual, resulta desproporcionado para la satisfacción de sus derechos, puesto que si ya se ha reconocido que las parejas del mismo sexo pueden constituir familia, «no hay razón lógica ni jurídica que explique una eventual negación del derecho del menor a tenerla». Aclaran que la condición de padres o madres de familia no está condicionada al género, en la medida en que «tanto amor, cuidado, apoyo, educación y demás aspectos relacionados con la crianza de un niño, pueden ser suministrados por padres heterosexuales como por padres homosexuales».

En segundo lugar, los demandantes afirman que existe una omisión legislativa relativa que desconoce la igualdad, el interés prevalente del menor en los procesos de adopción y el derecho a tener una familia.

La parte actora aborda el análisis desde esta perspectiva, señalando que si las parejas del mismo sexo pueden constituir familia y los menores tienen el derecho fundamental a ella, en virtud del interés superior del menor no existe razón para impedir que puedan ser adoptados por parejas del mismo sexo. Dejan en claro que si bien es cierto que existe una violación del derecho a la igualdad de las parejas del mismo sexo, «esta acción está dirigida a promover el derecho fundamental de las niñas, niños y adolescentes a tener una familia, que es prevalente sobre los derechos de los demás (art. $44 \mathrm{CP}$ )».

Argumentan que estas normas excluyen de ámbito de protección la adopción de menores por parte de parejas del mismo sexo, con lo cual se afecta el interés prevalente del menor, representado en su derecho fundamental a tener una familia (art. $44 \mathrm{CP}$ ). De acuerdo con los demandantes, «si la adopción se entiende como la principal medida de protección del menor y mecanismo que trata de hacer eficaz su garantía constitucional y fundamental a tener 
una familia, se debe resolver el presente problema constitucional dentro de los criterios de protección del menor y no solo a partir de la protección de las parejas del mismo sexo». Añaden que en esas condiciones la exclusión de las parejas del mismo sexo de la posibilidad de adoptar, más allá de un tratamiento desigual a las parejas homosexuales frente a las heterosexuales, termina generando «un preocupante déficit de protección al derecho de los menores a tener una familia».

Finalmente, los accionantes acusan «la existencia de una interpretación inconstitucional generalizada en el sector administrativo». Recuerdan que la Corte ha aceptado la posibilidad de someter a control constitucional las interpretaciones institucionales (judiciales o administrativas) que riñan con el estatuto superior y con las decisiones del Tribunal Constitucional (Auto 196 de 2005, Sentencias C-802 de 2008 y C-842 de 2010). Con esa premisa, sostienen que la interpretación que de la Ley 1098 de 2006 han efectuado el Instituto Colombiano de Bienestar Familiar - ICBF- y la Procuraduría General de la Nación no solo va en contravía del sentido fijado por la jurisprudencia constitucional, sino que infringe importantísimos derechos fundamentales como la igualdad y el derecho de los niños, niñas y adolescentes a tener una familia.

En el escrito de corrección de demanda explican que «las mismas razones que existen para controlar las interpretaciones de la ley realizadas de manera generalizada por los jueces, se pueden extender a las interpretaciones de la ley realizadas por funcionarios administrativos».

Ahora bien, en la Sentencia C-683 de 2015 se declararon constitucionales las expresiones impugnadas de los arts. 64, 66 y 68 (numerales 3 y 5) de la Ley 1098 de 2006, "por la cual se expide el Código de la Infancia y la Adolescencia», así como del art. 1 (parcial) de la Ley 54 de 1990, "por la cual se definen las uniones maritales de hecho y régimen patrimonial entre compañeros permanentes», bajo el entendido que, en virtud del interés superior del menor, dentro de su ámbito de aplicación están comprendidas también las parejas del mismo sexo que conforman una familia.

Las normas demandadas se refieren a los efectos jurídicos de la adopción, al consentimiento para la misma, a los requisitos para adoptar y a los elementos constitutivos de la unión marital de hecho. En el juicio de constitucionalidad, la Corte Constitucional determinó que las parejas del mismo sexo están habilitadas para adoptar conjuntamente, acorde con una lectura de las normas legales acusadas conforme con la Constitución Política y los tratados internacionales sobre derechos humanos, que consagran la protección del interés superior de los niños, niñas y adolescentes.

La Corte comenzó por precisar que la decisión reciente sobre la materia, contenida en la Sentencia C-071 de 2015, no impide un pronunciamiento 
sobre las normas demandadas. Aclara el Tribunal que ese fallo solo hizo tránsito a cosa juzgada relativa, por cuanto se centró en el examen de dos problemas jurídicos, referidos a los derecho a la igualdad y a la familia de las parejas del mismo sexo, pero no a los derechos de los niños desde la perspectiva del principio constitucional del interés superior del menor (CP art. 44).

Constató entonces que en la sentencia C-071 de 2015, la misma corporación había analizado si las normas sobre adopción vulneraban el derecho a la igualdad de las parejas del mismo sexo (CP art. 13) y desconocían también el derecho de las parejas del mismo sexo a constituir familia (CP art. 42). Sin embargo, en esa ocasión, la Corte decidió inhibirse en relación con el cargo de vulneración del interés superior del menor por considerar que se había configurado una ineptitud de la demanda en cuanto a ese cargo. En contraste, en esta oportunidad la Corte verificó que la demanda se dirigió adecuadamente contra las mismas normas, pero con un enfoque constitucional diferente, en la medida en que centra la discusión en torno al interés superior de los niños (CP art. 44).

En el presente caso la decisión de fondo (habilitar la adopción de niños por parejas del mismo sexo en virtud del interés superior del niño) tuvo como base los siguientes argumentos:

a) En primer lugar, la Corte señaló que los estudios científicos y las pruebas aportadas al proceso demostraban en forma dominante que la adopción por parejas del mismo sexo no genera afectaciones en el desarrollo integral de los niños, o bien que no está acreditada ninguna afectación a los niños que viven con parejas del mismo sexo. Aun cuando algunas intervenciones indicaban que los resultados no eran definitivos, la Corte verificó que no se refutaron las conclusiones prevalecientes y, en un caso, la objeción planteada fue inaceptable a la luz de la Constitución, por cuanto afirmaba que la homosexualidad es considerada como una patología, lo cual ha sido claramente desvirtuado.

b) En segundo lugar, la Sala Plena resaltó que según la Constitución, los tratados internacionales sobre derechos humanos, la jurisprudencia internacional y la jurisprudencia de esta Corte, la orientación sexual de una persona o su sexo, no son por sí mismos indicadores de falta de idoneidad moral, física o mental para adoptar; de modo que impedir que un niño tenga una familia, fundándose para ello únicamente en la orientación sexual o el sexo de una persona o de una pareja, representa una restricción inaceptable de los derechos del niño, y es entonces además contrario a su interés superior, protegido por la Constitución y los instrumentos que se integran a ella. 
c) En tercer lugar, la Corte reconoció que una lectura conforme con la Constitución indica que, desde la perspectiva de la protección al interés superior del niño, la ley debe entenderse como neutra al sexo de las parejas y a la orientación sexual de quienes las conforman.

Por otra parte, la Corte advirtió que, en vista de que no se encuentra acreditado de manera concluyente que los menores sufran o puedan sufrir algún tipo de afectación en su desarrollo armónico e integral por el hecho de ser adoptados o crecer en el entorno de una familia conformada por parejas del mismo sexo, excluir a estas últimas del universo de potenciales adoptantes implica una limitación del derecho de los niños a tener una familia y no ser separados de ella, que afecta injustificada, irrazonable y desproporcionadamente su interés superior (CP art.44).

Por último, el Alto Tribunal verificó y reafirmó que tiene competencia y legitimidad para intervenir en la resolución de este caso. No solo porque la Constitución así se lo reconoce expresamente en el art. 241, sino además porque se trata de proteger derechos de población vulnerable, como los niños en situación de adoptabilidad, frente a una interpretación de la ley que no es conforme con el principio de interés superior del menor, en un contexto en el cual los niños son una población en desventaja en términos representativos, cuyos derechos debe proteger el juez al margen de la decisión de las mayorías políticas. Es precisamente en estos casos, para garantizar los derechos de grupos vulnerables y sin representación democrática específica, que se justifica la función de control constitucional a la actividad del legislador.

La Corte aclaró que cualquier proceso de adopción debe estar siempre dirigido a garantizar el interés superior del menor y el restablecimiento de sus derechos y, por tanto, en todo caso, será deber del Estado verificar, conforme a la Constitución y en los términos de la sentencia, si se cumplen los demás requisitos establecidos en el ordenamiento jurídico. La Corte quiso resaltar que las dudas y temores acerca de si la sociedad está preparada para asumir esta decisión no se disipan negando una inocultable realidad sino enfrentando sus desafíos.

\section{UNA DECISIÓN ACTIVISTA DE LA JUSTICIA CONSTITUCIONAL EN CLAVE DEL INTERÉS SUPERIOR DEL MENOR}

El análisis de constitucionalidad realizado por la Corte ya no consiste en definir si la exclusión de las parejas del mismo sexo de la posibilidad de participar en los procesos de adopción de niños, niñas y adolescentes vulnera los derechos de las parejas a la igualdad y a conformar una familia, lo cual fue desestimado por la mayoría de la Sala en la Sentencia C-071 de 2015. Lo que 
en esta oportunidad se encarga de determinar la Corte es, desde un enfoque constitucional diferente, si las normas que regulan el régimen legal de adopción en Colombia, al excluir a las parejas del mismo sexo de la posibilidad de participar en procesos de adopción, vulnera el principio del interés superior del menor, representado en su derecho a tener una familia para garantizar su desarrollo armónico e integral (art. $44 \mathrm{CP}$ ). Ahora bien, no cabe duda que, en el fondo, con esta decisión también la Corte reconoció un déficit de protección por parte del legislador a los derechos de las parejas del mismo sexo.

Tal y como se ha señalado en ediciones anteriores de este Anuario, la Constitución de 1991, entre los mecanismos que previó para la protección de los derechos fundamentales están la acción pública de inconstitucionalidad y la acción de tutela. Es a través de estas dos garantías judiciales, especialmente cuando se analiza la constitucionalidad de las normas, como la Corte ha realizado en mayor medida un activismo judicial que, en este caso, ha derivado en el reconocimiento del derecho a la adopción de las parejas del mismo sexo en Colombia, lo que se ha erigido en una forma de acatar por vía judicial uno de los grandes cambios que a nivel social y cultural se han presentado en el mundo.

En Colombia, la adopción de una constitución más garantista vino acompañada del fortalecimiento de la rama judicial, lo que implicó un incremento de su independencia y eficiencia, y la atribución de facultades para la garantía y protección de derechos y el control de los abusos de los órganos políticos $^{21}$.

Cuando se dio una de las primeras decisiones activistas en la justicia, como fue el caso Brown vs. Borrad of Education de la Corte Suprema de Estados Unidos en 1954, por medio del cual se dispuso la inconstitucionalidad de la segregación racial en las escuelas norteamericanas, se generó cierta tensión y resistencia que lentamente se fue desvaneciendo para aceptar que las decisiones judiciales tenían un tinte activista e impredecible. Actualmente, la actitud activista hace parte de la cultura jurídica de los operadores judiciales, lo cual, así implique interpretaciones minoritarias, debe ser visto con naturalidad siempre que no raye en la arbitrariedad y se respeten las garantías y principios constitucionales ${ }^{22}$.

En el caso de la sentencia C-683 de 2015, la Corte Constitucional de Colombia, mediante una posición activista condiciona la constitucionalidad de las normas demandadas. La Corte evidencia la exclusión o segregación generada por el legislador en relación con la posibilidad de que las parejas del

21 Uprimny, R. (2011).

22 Mejía Turizo, J. y Pérez Caballero, R. (2015). 
mismo sexo puedan adoptar niñas, niños y adolescentes, lo que constituye una vulneración del derecho y principio constitucional del interés superior del menor, representado en su derecho a tener una familia para garantizar su desarrollo armónico e integral (art. $44 \mathrm{CP}$ ).

Las razonamientos judiciales se centraron en que la garantía del principio constitucional del interés superior del niño aporta un enfoque nuevo para realizar una interpretación adecuada de la norma que se ajuste a los cambios sociales y culturales en materia de inclusión y protección de un grupo que no es políticamente dominante, como el de las parejas del mismo sexo.

En contraste con la sentencia objeto de análisis, los principios determinantes para la emisión de otros fallos de la Corte Constitucional sobre la materia fueron, por ejemplo, el pluralismo y la igualdad. En sentencias como la T-290 de 1995 y la C-071 de 2015, la Corte Constitucional recalcó el deber del Estado respecto a la promoción del pluralismo, principio bajo el cual es factible la protección de los diferentes tipos de familia. En esta medida, la orientación sexual no es un criterio excluyente para el acceso a la adopción.

Aunque el principio del interés superior del menor sí había sido utilizado por la Corte Constitucional de Colombia en la sentencia C-814 de 2001, esto había sido con el fin de fundamentar una interpretación tradicional del concepto de familia del art. 42 de la Constitución Política. Esta sentencia acudía a la moralidad para referirse a la condición que debían cumplir los adoptantes, sin tener en cuenta que la noción de moral tiene un carácter meramente subjetivo. Sin embargo, algunos magistrados presentaron salvamente un voto en el que recalcaron nuevamente la importancia del pluralismo y emplearon el concepto de la evolución social como componente determinante para la interpretación de la Constitución, y defendieron la inclusión de las parejas del mismo sexo dentro del término familia, que hoy en día, quince años después, aunque un sector considerable de la sociedad colombiana rechace, la Corte Constitucional respalda plenamente.

Fue con la sentencia T-276 de 2012, que la Corte permitió la adopción por parte de una persona homosexual argumentando la prevalencia del principio del interés superior del menor, y en donde se sostiene que la orientación sexual de una persona no constituye per se una amenaza o riesgo para el menor, lo que en definitiva es un parámetro claramente diferente del concepto tradicional de familia que se venía trabajando. Se consideró que la separación del núcleo familiar de los menores, sin que exista una razón suficiente o de inminente peligro constituye una clara vulneración del principio del interés superior del menor por parte de las entidades públicas, que estarían generando la amenaza hacia los niños. 
Más recientemente, en la sentencia de la Sala Plena de la Corte Constitucional SU-617 de 2014, se resolvió que en el caso de la adopción por consentimiento, esto es cuando una persona adopta el hijo biológico de su compañero/a permanente, la condición de homosexual de la pareja adoptante no puede ser fundamento para resolver negativamente el respectivo trámite administrativo, so pena de constituir una vulneración a los derechos fundamentales a tener una familia y a la autonomía y unidad familiar de las dos personas que conforman la pareja y del menor en proceso de ser adoptado ${ }^{23}$.

En la sentencia objeto de estudio en esta oportunidad, la C-683 de 2015, se realiza una interpretación garantista del principio del «interés superior del menor» al considerar que este principio se protege cada vez que el Estado puede proporcionar a los niños que lo requieran un hogar donde se les brinde el amor, el cuidado y la protección que no pudieron obtener de su hogar biológico, independientemente de que se trate de un hogar homoparental, en tanto lo importante no es la orientación sexual de los padres, sino el cumplimiento de los requisitos de ley para poder ser considerados aptos para la adopción. Se observa entonces una evolución en la jurisprudencia constitucional, que permite afirmar que hoy en día, por lo menos desde el punto de vista jurídico, las parejas del mismo sexo en Colombia podrán ser padres adoptantes en iguales condiciones que las parejas heterosexuales, porque lo que prima son los derechos de los niños a tener una familia.

\section{BIBLIOGRAFÍA}

Botero, E. (1990). Homofilia y Homofobia, estudio sobre la homosexualidad, la bisexualidad y la represión de la conducta homosexual. Colombia.

Chaux, E. (2008). Educación, convivencia y agresión escolar. Bogotá: Ediciones Uniandes.

Mejía Turizo, J. y Pérez Caballero, R. (2015). Activismo judicial y su efecto difuminador en la división y equilibrio de poderes. Justicia, 27, 30-41.

Robledo, P. (2014). La jurisprudencia Constitucional Colombiana en el año 2014. Anuario Iberoamericano de Justicia Constitucional, 18, 591-624.

Uprimny, R. (2011). Las transformaciones constitucionales recientes en América Latina: tendencias y desafíos. En C. R. Garavito (ed.). El derecho en América Latina: Un mapa para el pensamiento jurídico del siglo XXI. Buenos Aires: Siglo Veintiuno Editores.

Secretaría de Gobierno de Bogotá (2008). Estudio sobre violencia escolar en Bogotá. Bogotá: Secretaría de Gobierno de Bogotá.

23 Véase Robledo, P. (2014). 


\section{JURISPRUDENCIA}

Corte Constitucional de Colombia, Sentencia T-290 de 1995.

Corte Constitucional de Colombia, Sentencia C-814 de 2001.

Corte Constitucional de Colombia, Sentencia C-482 de 2002.

Corte Constitucional de Colombia, Sentencia C-640 de 2010.

Corte Constitucional de Colombia, Sentencia T-949 de 2011.

Corte Constitucional de Colombia, Sentencia T-276 de 2012.

Corte Constitucional de Colombia, Sentencia C-071 de 2015.

Corte Constitucional de Colombia, Sentencia T-565 de 2013.

Corte Constitucional de Colombia, Sentencia SU-214 de 2016.

Consejo de Estado, Sección Tercera, Sentencia de 30 de septiembre del 2000, exp. 13.329.

Consejo de Estado, Sección Tercera, Sentencia de 23 de septiembre de 2009, exp. 18272.

Consejo de Estado, Sección Tercera, Sentencia de 5 de marzo de 2004, exp. 1996-00432 01. 